Ambiente \& Água - An Interdisciplinary Journal of Applied Science
ISSN 1980-993X - doi:10.4136/1980-993X
www.ambi-agua.net
E-mail: ambi-agua@agro.unitau.br

\title{
Indicadores como instrumento de manejo integrado de microbacia hidrográfica
}

\author{
doi: 10.4136/ambi-agua.1369
}

Received: 16 Aug. 2013; Accepted: 08 Dec. 2013

\author{
Roxane Lopes de Mello ${ }^{1 *}$; Nelson Wellausen Dias ${ }^{2}$; Maria de Jesus Robim ${ }^{3}$ \\ ${ }^{1}$ Programa de Pós-graduação em Ciências Ambientais (PPG-CA) \\ Universidade de Taubaté, Taubaté, SP, Brasil \\ ${ }^{2}$ Instituto Brasileiro de Geografia e Estatística, (IBGE), Aracaju, SE, Brasil \\ ${ }^{3}$ Instituto Florestal, (IF) \\ Secretaria de Meio Ambiente do Estado de São Paulo, São Paulo, SP, Brasil \\ *Autor correspondente: e-mail: mellodias.slp@gmail.com, \\ nwdias@gmail.com, mjesusrobim@gmail.com
}

\section{RESUMO}

Os problemas ambientais em nível de bacias hidrográficas são complexos e requerem soluções para minimizar impactos socioeconômicos, ambientais e político-institucionais. Um paralelo acerca de conceitos relativos ao desenvolvimento sustentável, agricultura sustentável, bacias hidrográfica, microbacias hidrográficas, bem como o uso de indicadores para medir a sustentabilidade local, é de suma importância no âmbito do desenvolvimento local sustentável. O presente trabalho teve como objetivo coletar dados relacionados com as práticas de gestão territorial e de desenvolvimento rural nas microbacias do ribeirão Cachoeirinha e córrego do Meio, no município de São Luiz do Paraitinga, SP, para, a partir das análises desses dados, propor indicadores de sustentabilidade voltados para a gestão integrada das duas microbacias e a promoção do desenvolvimento sustentável na comunidade local. Os indicadores devem ter como base a sustentabilidade das atividades da microbacia e também devem ser ferramentas úteis para operacionalizar o desenvolvimento sustentável e servir de referência no processo decisório. Os procedimentos metodológicos para a caracterização geral da área e da comunidade envolvidas foram os levantamentos de campo e de fontes documentais. A definição dos critérios para a delimitação da área baseou-se nos limites da microbacia propostos pelo Programa Estadual de Microbacias Hidrográficas desenvolvido pelo Governo do Estado de São Paulo, por meio da Secretaria de Agricultura e Abastecimento. Os resultados levaram ao desenvolvimento de 83 indicadores de sustentabilidade, bem como à necessidade de articulação dos setores da região para adoção de estratégias que busquem o desenvolvimento sustentável local.

Palavras-chave: indicadores de sustentabilidade, práticas rurais sustentáveis, desenvolvimento local sustentável, Ribeirão das Cachoeirinhas, Córrego do Meio, Catuçaba, São Luiz do Paraitinga.

\section{Environmental indicators as an integrated management instrument for watersheds}

\begin{abstract}
Environmental problems at the watershed level are complex and require solutions that minimize socioeconomic, environmental, and political-institutional impacts. Within this context, a crosscutting analysis of concepts related to sustainable development, sustainable
\end{abstract}


agriculture, watershed structure, and the use of indicators to measure local sustainability is of paramount importance for planning development at the local level. The objective of this research was to collect information related to management practices and rural development regarding the watersheds of Ribeirão Cachoeirinha and Córrego do Meio in the municipality of São Luiz do Paraitinga, SP. The goal was to propose sustainability indicators that would support an integrated watershed management strategy and promote sustainable development. Indicators should be based on the sustainability of watershed activities, be useful tools for implementing sustainable development and serve as reference in the decision-making process. Methods involved a general characterization of the area and the community using field surveys and published sources. The criteria utilized for defining the boundaries of the area were based on the Watershed State Program developed by the Agriculture and Supply Secretariat of the State of São Paulo. The results led to the development of 83 sustainability indicators and indicated the need for the community to develop an integrated strategy to promote local sustainable development.

Keywords: rural sustainable practices, local sustainable development, Ribeirão das Cachoeirinhas and Córrego do Meio, Catuçaba District, São Luiz do Paraitinga.

\section{INTRODUÇÃO}

Os seres humanos convivem em sociedade, e a aventura dessa convivência os desafia a enfrentar a responder, a todo o momento, a seguinte indagação: "Como agir na relação com os outros seres e com o nosso planeta?”. Trata-se de uma pergunta fácil de ser formulada, mas difícil de ser respondida. Sabemos que as pessoas não nascem boas ou más; é a sociedade quer queira, quer não, que educa moralmente seus membros. A família, os meios de comunicação e o convívio com outras pessoas influenciam marcantemente o comportamento de crianças, adolescentes e adultos (Brasil, 1998).

Segundo D'Ambrosio (1998), um homem reúne em seus hábitos e atitudes tudo aquilo que ouviu, observou, enxergou, leu, refletiu, enfim, vivenciou, buscando, ao longo de sua vida, sobreviver e transcender. Assim, a espécie desenvolveu o que talvez seja sua característica mais distintiva: o sentido do tempo, passado e futuro, aparentemente inexistente nas demais espécies animais.

Diversos autores concordam com a ideia de que se vive um momento crítico na história da humanidade, uma crise global que se manifesta no âmbito social, ambiental, moral e existencial. Entretanto, toda crise tem seus riscos e oportunidades e, ao longo da história da civilização, o ser humano precisou parar, refletir e reavaliar sua visão de homem e de mundo, e também sua posição no universo, para reformular paradigmas que reorientassem o seu desenvolvimento (Hoyos Guevara, 1998).

A demanda global por recursos naturais deriva de uma formação econômica com base na produção e no consumo em larga escala. A lógica, associada a essa formação que reage ao processo de exploração da natureza, é responsável por boa parte da destruição dos recursos naturais. É criadora de necessidades que exigem, para sua própria manutenção, um crescimento sem fim das demandas quantitativas e qualitativas desses recursos (Gonçalves, 2001).

Com o lançamento do relatório de Brundtland, pela Comissão Mundial sobre o Meio Ambiente, o ideal da sustentabilidade foi amplamente divulgado, surgindo, a partir de então, inúmeras definições para "agricultura sustentável". A maior delas procura expressar a necessidade de estabelecimento de um novo padrão produtivo que não agrida o meio ambiente e que mantenha as características do ecossistema (Ehlers, 1999).

Como ilustra o Plano de Ação do Banco Mundial, "From Vision to Action in the Rural Sector" (Dumanski e Piere, 2000), há claramente maior demanda, em níveis nacionais e 
globais, para uma crescente produção e intensificação agrícola, mas o maior desafio é alcançar, conjuntamente, a manutenção da qualidade dos recursos naturais. O termo agricultura sustentável passou a fazer parte do vocabulário de todos os setores, inclusive nas atividades rurais. Entretanto, o seu conceito operacional ainda não está claro (Quirino, 1990). Mesmo diante dessas indefinições, a inclusão das questões ambientais no contexto da produção agropecuária é um avanço em busca da sustentabilidade.

O principal conceito envolvido nas concepções metodológicas do presente trabalho é o da sustentabilidade e, em concordância com Sachs (1989), para alcançar a sustentabilidade ambiental há necessidade de considerar, simultaneamente, os aspectos sociais, com objetivo de reduzir as distâncias quanto ao padrão de vida, nos grupos sociais.

$\mathrm{Na}$ busca pelo desenvolvimento local sustentável, podem-se delimitar as regiões rurais em microbacia hidrográfica, que é uma unidade básica de planejamento para a compatibilização da preservação dos recursos naturais e da produção agropecuária. As microbacias apresentam características ecológicas, geomorfológicas e sociais integradoras, o que possibilita uma abordagem holística e participativa, envolvendo processos interdisciplinares para estabelecimento de formas de promoção do desenvolvimento sustentável local. O desenvolvimento local está associado, normalmente, a iniciativas inovadoras e mobilizadoras da coletividade, articulando as potencialidades locais nas condições dadas pelo contexto. Como diz Haveri (1996), “[...] as comunidades procuram utilizar suas características específicas e suas qualidades superiores e se especializar nos campos em que têm uma vantagem comparativa com relação às outras regiões". As experiências bem sucedidas de desenvolvimento local são resultado de uma vontade conjunta da sociedade que dá sustentação e viabilidade política a iniciativas e ações para organizar energias e promover a dinamização e transformação da realidade (Castells e Borja, 1996).

O desenvolvimento local sustentável é o "[...] processo de mudança social e de elevação das oportunidades da sociedade, compatibilizando, no tempo e no espaço, o crescimento e a eficiência econômica, a conservação ambiental, a qualidade de vida e a equidade social, partindo de um claro compromisso com o futuro e a solidariedade entre gerações" (Buarque e Bezerra, 1994).

Para avaliação dos resultados dos projetos desenvolvidos em comunidades rurais na busca da sustentabilidade, é necessária a implementação de um programa de monitoramento socioeconômico e ambiental no âmbito de uma microbacia. Para tanto, a identificação de indicadores de sustentabilidade torna-se fundamental.

Assim, o objetivo deste estudo é caracterizar o uso e cobertura do solo na microbacia do ribeirão da Cachoeirinha e do córrego do Meio, identificando as práticas econômicas, ambientais e sociais historicamente adotadas, a fim de identificar fatores que promovam a sustentabilidade nessa microbacia.

\section{MATERIAL E MÉTODOS}

\section{1. Área de estudo}

Este trabalho foi realizado na microbacia hidrográfica do córrego da Cachoeirinha e do córrego do Meio (ou córrego da Queimada), que possui área de 3.309 hectares e que está localizada no distrito de Catuçaba, no município de São Luiz do Paraitinga (Figura 1). Esta é uma microbacia selecionada pela Coordenadoria de Assistência Técnica Integral - CATI, em 2000, para compor o Programa Estadual de Microbacias Hidrográficas. 


\subsection{A microbacia do ribeirão da Cachoeirinha e do córrego do Meio}

São Luiz do Paraitinga, SP é uma cidade turística, na região do alto Paraíba, que detém um riquíssimo patrimônio histórico, tombado pelo CONDEPHAAT (Conselho de Defesa do Patrimônio Histórico, Arqueológico, Artístico e Turístico) e IPHAN (Instituto do Patrimônio Histórico e Artístico Nacional), composto pelo maior conjunto arquitetônico dos séculos XV a XIX do Estado de São Paulo. Seu valor histórico é constituir um retrato da fase áurea do café na economia paulista.

O município está localizado no vale do Paraíba, na região conhecida como planalto Paraitinga/Paraibuna. Possui área de $737 \mathrm{~km}^{2}$, segundo IBGE (2006), e população de 10.727 habitantes, com densidade populacional de 14,55 habitantes $/ \mathrm{km}^{2}$. A economia do município é bastante limitada, e o Índice de Desenvolvimento Humano Municipal (IDHM) atinge 0,754. A população local possui baixa renda familiar, e $80 \%$ das famílias sobrevivem com renda entre um e um e meio salários mínimos (IBGE, 2006).

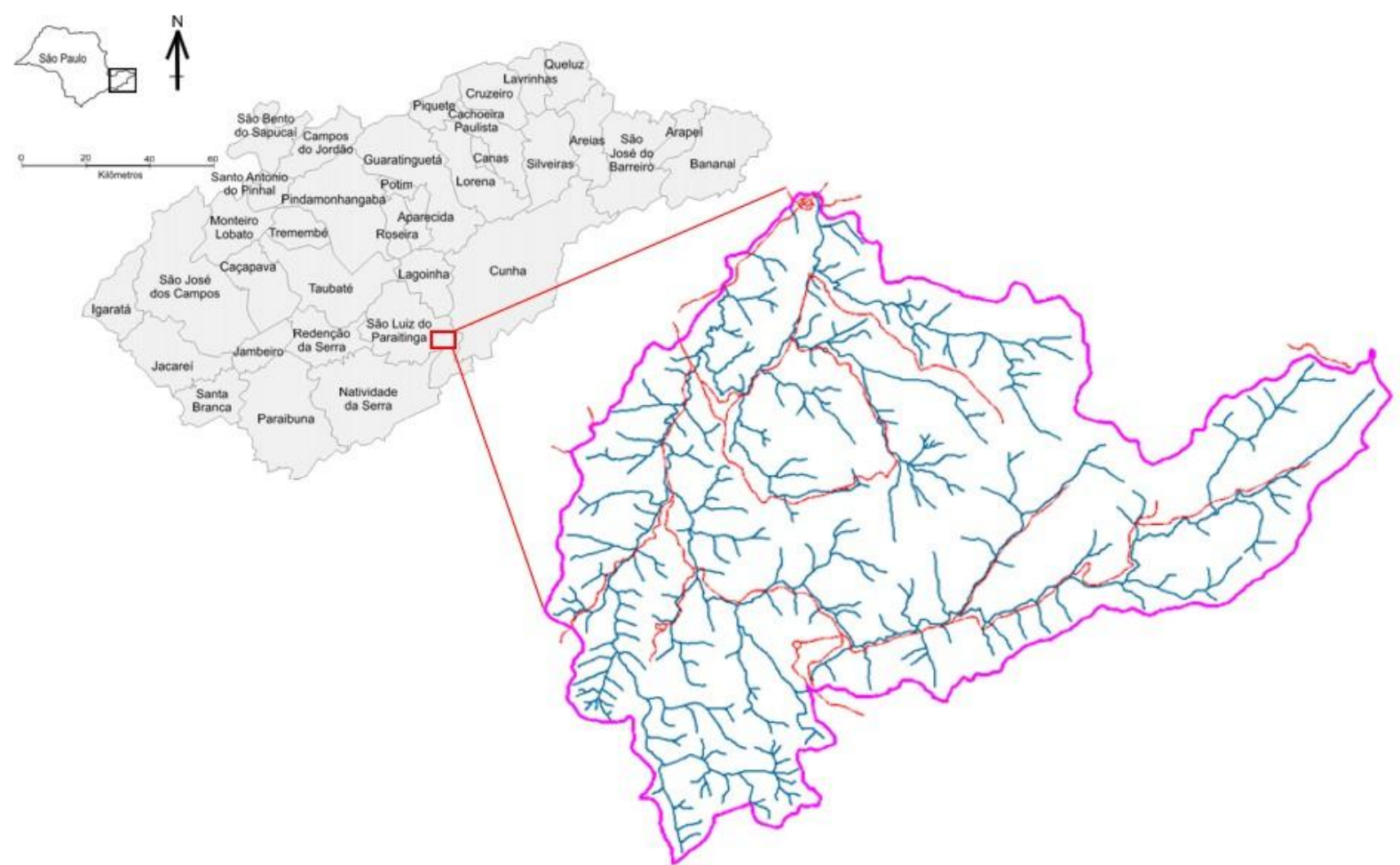

Figura 1. Localização da microbacia do ribeirão da Cachoeirinha e do córrego do Meio no município de São Luiz do Paraitinga, SP.

Segundo o Inventário Florestal do Estado de São Paulo, realizado em 2005 pelo Instituto Florestal, o município possuía 20,6\% de sua área total coberta por florestas nativas; $8 \%$ com reflorestamentos e $71,4 \%$ com pastagens, sendo a maioria considerada degradada. Da cobertura florestal nativa ainda existente, cerca de $70 \%$ encontra-se no interior do Parque Estadual da Serra do Mar - Núcleo Santa Virgínia -, junto com a sua Zona de Amortecimento. Foram encontrados no município 732 fragmentos florestais e $80 \%$ deles são menores que 10 hectares, representando uma grande fragmentação da paisagem, principalmente do bioma Mata Atlântica.

Pertencente à bacia hidrográfica do rio Paraíba do Sul, o município e sua região possuem terras distribuídas pelas principais bacias hidrográficas formadoras do rio Paraíba do Sul, denominadas bacia do rio Paraibuna e do rio Paraitinga. O mau uso do solo e a remoção da cobertura florestal nativa vêm sendo praticadas, há décadas, de forma indevida, principalmente por meio do uso de técnicas equivocadas de manejo de solos, como aração 
morro abaixo e uso constante do fogo para formação de pastagem. Vários remanescentes de campo sujo estão cobertos por gramíneas como o sapê (Imperata brasiliensis) e samambaiais bioindicadoras, como o Piteridium aquilinum, natural de solos exauridos, ácidos e com grande teor de alumínio. Nas áreas de pasto, preferencialmente, são encontradas gramíneas exóticas, como as do gênero Brachiaria spp (São Paulo, 1998).

\subsection{Distrito de Catuçaba}

O distrito de Catuçaba (Figura 2) localiza-se ao sul do município de São Luiz do Paraitinga, no entorno do Parque Estadual da Serra do Mar, e divide-se em uma vila e a zona rural. Localizado no planalto do Paraitinga, é caracterizado como um território típico de "Mares de Morros", com alguns remanescentes de mata atlântica (Skorupa, 2003).

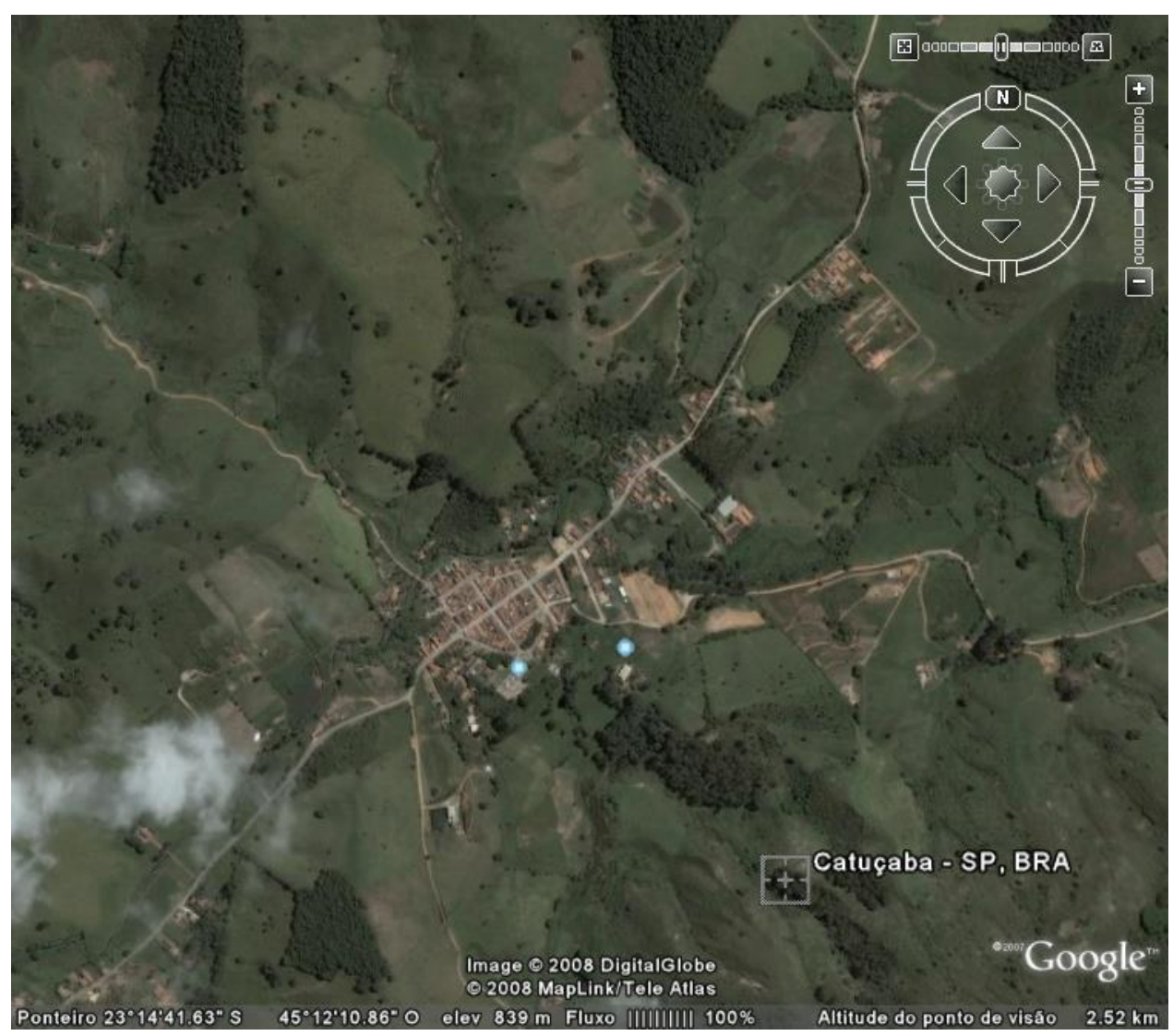

Figura 2. Visão geral do Distrito de Catuçaba.

Fonte: www.fraps.com

A característica topográfica da região, aliada às características socioeconômicas do distrito, gera dificuldades para os produtores, quanto ao manejo do solo e, consequentemente quanto a sua produção. Dessa forma, os produtores não conseguem otimizar o espaço das propriedades e ficam sem alternativa de renda, o que provoca o êxodo rural.

\subsection{Procedimentos metodológicos}

O método de investigação usado nesta pesquisa foi o comparativo, uma vez que viabilizou a comparação de variáveis sociais, econômicas e ambientais. Quanto à natureza, é uma pesquisa aplicada e qualitativa. Quanto aos procedimentos de pesquisa, caracteriza-se como um estudo de caso. A microbacia do ribeirão da Cachoeirinha e do córrego da Queimada foi escolhida como objeto de estudo por já existirem estudos prospectivos em relação a várias alternativas de intervenção na bacia realizadas pela Secretaria de Agricultura 
e Abastecimento do Estado de São Paulo, por meio da Coordenadoria de Assistência Técnica Integral - CATI e da Casa da Agricultura local.

Para a seleção de indicadores de sustentabilidade para a comunidade em estudo, usou-se o modelo proposto pela Comissão de Desenvolvimento Sustentável - CDS, das Nações Unidas, seguido no Brasil pelo Instituto Brasileiro de Geografia e Estatística - IBGE, que organiza os indicadores em quatro dimensões de sustentabilidade: social, ambiental, econômica e institucional.

A dimensão social corresponde aos objetivos ligados à satisfação das necessidades humanas, melhoria da qualidade de vida e justiça social. Os indicadores incluídos nessa dimensão abrangem os temas: população, trabalho e rendimento; saúde; educação; segurança social, justiça e habitação. Com isso, procura-se retratar a situação social, a distribuição de renda e as condições de vida da população, apontando o sentido de sua evolução recente.

A dimensão ambiental diz respeito ao uso dos recursos naturais e à degradação ambiental, e está relacionado aos objetivos de preservação e conservação do meio ambiente, considerados fundamentais ao beneficio das gerações futuras, envolvendo-se temas como água, resíduos sólidos, terra, biodiversidade e saneamento.

A dimensão econômica trata do desempenho macroeconômico e financeiro e dos impactos no consumo de recursos materiais e uso de energia primária. É uma dimensão com objetivos de promover eficiência dos processos produtivos e alterações nas estruturas de consumo, orientadas a uma reprodução econômica sustentável em longo prazo.

A dimensão institucional diz respeito à orientação política, capacidade e esforço despendido para as mudanças requeridas para a efetiva implementação do desenvolvimento sustentável.

De forma geral, pode-se dizer que indicadores são parâmetros ou funções derivadas deles que descrevem um estado ou uma resposta dos fenômenos que ocorrem em um meio (Santos, 2004).

Ao nível da escala da propriedade, essas abordagens conduzem a indicadores que ilustrem diversos conceitos chave (Landais, 1998). A viabilidade implica, em termos econômicos, a securitização das fontes de recursos do sistema de produção agrícola em face das variáveis do mercado e das incertezas ligadas à agricultura. Os indicadores usuais de resultados econômicos dão conta desse conceito, ao menos, nas atuais circunstâncias econômicas. Em seguida, a vivenciabilidade: a atividade agrícola deve assegurar uma vida decente, profissional e pessoalmente, ao trabalhador e sua família. Indicadores poderão situar o agricultor em relação a certas referências sociais, por exemplo, a renda ou o tempo de trabalho, mas poderão também abordar aspectos mais subjetivos, como a participação na vida comunitária ou na abertura ao relacionamento com outros atores da sociedade. A terceira é a transmissibilidade do capital da propriedade no senso amplo, pois, além de chamar para si indicadores monetários de avaliação da empresa agrícola, também atrai indicadores que englobam o estado ou as tendências que afetam os recursos naturais utilizados na agricultura, como fertilidade do solo, energia, os insumos ou água de irrigação. Por fim, a reprodutibilidade ambiental dos ecossistemas ligada às propriedades: trata-se de situar, com a ajuda de indicadores, como os de pressão sobre os recursos hídricos ou fatores edáficos, os efeitos das práticas das propriedades sobre o meio ambiente. Na maior parte dos casos, esses indicadores darão conta, antes de tudo, dos riscos para o meio ambiente ligado às atividades agrícolas.

Para determinar os indicadores de sustentabilidade da área objeto deste estudo, foram utilizados atributos de sustentabilidade obtidos a partir de dados secundários, oriundos de outros estudos anteriores realizados na região pela CATI e pela Organização NãoGovernamental AKARUI - Associação para Cultura, Meio Ambiente e Cidadania, sediada no município de São Luiz do Paraitinga. 


\section{RESULTADOS E DISCUSSÃO}

A microbacia do ribeirão da Cachoeirinha e do córrego da Queimada possui área total de 3.309,1 hectares. Devido às características geomorfológicas dessa região, conhecida como "mares de morros", típica da porção mais a montante da bacia do rio Paraíba do Sul, onde se insere a área de estudo, dois fatores são fundamentais para determinar os tipos de uso possível das terras: declividade e tipos de solo. A Tabela 1 apresenta as principais características desses dois fatores.

Tabela 1. Percentagem de cobertura territorial dos tipos de solo e classes de declividade presentes na microbacia do ribeirão da Cachoeirinha e córrego do Meio.

\begin{tabular}{lccc}
\hline Solos conforme mapa do PEMH & $\begin{array}{c}\text { Percentual da } \\
\text { Área (\%) }\end{array}$ & Classes de declividade & $\begin{array}{c}\text { Percentual da } \\
\text { Área (\%) }\end{array}$ \\
\hline Latossolo Vermelho Amarelo & 19,7 & $0-3 \%$ & 1,0 \\
Cambissolo & 11,5 & $3-5 \%$ & 1,5 \\
Solo hidromórfico & 2,6 & $5-12 \%$ & 11,4 \\
Podzólico Vermelho Amarelo & 0,7 & $12-20 \%$ & 14,2 \\
Solos podzolizados com cascalho & 65,5 & $20-40 \%$ & 47,6 \\
& & $>40 \%$ & 24,3 \\
\hline
\end{tabular}

Fonte: Programa Estadual de Microbacias Hidrográficas (PEMH), CATI, 1999.

Predominantes na bacia são, preponderantemente, solos podzolizados com cascalho (classificados como Argissolo pela Embrapa), que apresentam risco de serem erodidos com o uso em pastagem. Esses solos associados a fortes declividades tornam-se uma limitação para a pecuária. Já para a agricultura são considerados regulares, pois são geralmente ácidos e esgotados, necessitando de correção e adubação. Os latossolos vermelho amarelos (Latossolo VA, segundo a Embrapa) cobrem cerca de $20 \%$ da área da microbacia e, para agricultura, são considerados regulares e não adequados, pois apresentam problema de fertilidade e com o tempo de uso se tornam ácidos e com pequena retenção de bases por parte das argilas. Ainda que eles sejam friáveis, profundos e de fácil penetração das raízes, por terem baixa capacidade de retenção de água tornam-se propícios à erosão e apresentam restrições para a mecanização, devido ao relevo acentuado. Para pecuária, não apresentam grandes problemas; porém, devido à baixa fertilidade, exigem aplicação correta de fertilizantes e corretivos (Arguello e Sausen, 2007). Quanto às classes de declividade, a tabela mostra claramente a predominância das classes mais declivosas totalizando cerca de $72 \%$ da área com declividade acima de $20 \%$.

A perda da cobertura florestal e o quadro de uso inadequado do solo e de suas consequências socioeconômicas, observadas em geral na bacia do rio Paraitinga, repetem-se na microbacia em estudo. Visitas técnicas, diagnósticos e projetos realizados no local, desde 2001, pela Casa da Agricultura de São Luiz do Paraitinga, e de 2007, pela AKARUI, evidenciam a intensa degradação das áreas de preservação permanentes (APP), caracterizada pela ocupação antrópica ilegal das áreas destinadas à vegetação ciliar e pela falta de conservação do solo, principalmente, nas pastagens degradadas. Reuniões promovidas pela AKARUI com os proprietários de terras na bacia, no ano de 2008 , confirmam essa situação e a baixa produtividade das atividades econômicas naquela região.

A produção das culturas perenes e temporárias presentes na microbacia é quase insignificante e não apresenta diversificação, estando voltada para a agricultura de subsistência, ou seja, a produção é suficiente para as necessidades do proprietário da terra e sua família. Essas culturas são desenvolvidas com técnicas rudimentares, que passam de geração para geração sem as devidas técnicas conservacionistas, por meio de técnicas equivocadas de manejo de solos, como aração morro abaixo e uso constante do fogo como 
instrumento de limpeza para formação de pastagem. Vários remanescentes de campo sujo estão cobertos por gramíneas, como o sapê (Imperata brasiliensis) e samambaias bioindicadoras, como o Piteridium aquilinum, natural de solos exauridos, ácidos e com grande teor de alumínio. Nas áreas de pasto, preferencialmente, são encontradas gramíneas exóticas introduzidas, principalmente as do gênero Brachiaria spp. A ocupação predatória e a adoção de sistemas de produção agrícolas rudimentares provocaram a devastação de florestas, a erosão dos solos e a perda de potencial hídrico em praticamente toda a microbacia. Além disso, a construção das estradas rurais foi feita sem considerar o comportamento hídrico, transformando-as em canais escoadouros de águas e de sedimentos, o que tem agravado os problemas erosivos e provocado o assoreamento de córregos e rios.

Portanto, a área da microbacia - com seus diversos tipos de solo, declividades e tipos de uso - está susceptível à degradação, se o manejo agrícola não for adequado, possibilitando boa cobertura do solo e aplicação de práticas conservacionistas. Essas práticas irão promover a infiltração da água da chuva e seu armazenamento no solo, diminuindo o escoamento superficial. Tais práticas devem ser usadas com a finalidade de aumentar a resistência do solo e ou diminuir as forças dos elementos causadores dos processos erosivos. No entanto, deve-se salientar que a densidade da cobertura vegetal é o principal fator determinante da conservação dos solos.

\subsection{Indicadores econômicos ou de capacidade produtiva}

Os indicadores econômicos procuram demonstrar a produtividade efetiva da propriedade rural, bem como a renda gerada por ela ao proprietário e seus familiares.

Abordam-se aqui as práticas e comportamentos dos agricultores avaliados conforme escalas precedentes, do ângulo econômico. Nas condições do mercado, a agricultura familiar deve resgatar uma renda suficiente para assegurar ao agricultor certa autonomia em suas escolhas e permitir-lhe orientação em direção à tentativa de sustentabilidade. Os indicadores apresentados (Tabela 2) resumem os aspectos essenciais da sustentabilidade econômica da agricultura familiar local.

$\mathrm{O}$ primeiro componente concerne à viabilidade econômica em curto prazo da propriedade, apreciada segundo a renda bruta da produção para cada unidade de trabalho familiar, mas também pela análise da contribuição das diversas produções a sua renda agrícola. A ideia é de que uma diversificação da produção torna a propriedade menos sensível às altas e baixas do mercado, sendo, por isso, mais viável.

- Infraestrutura atual: de serviços (água, atendimento médico, acessos e circulação, eletricidade, meios de comunicação), transporte e segurança.

- Educação: em todas as suas modalidades como base para qualquer sistema produtivo.

- Participação da comunidade por meio de associações, cooperativas, organizações não governamentais.

Os indicadores do desenvolvimento econômico propostos na Tabela 2 podem ser colocados como:

- Crescimento econômico: esse indicador pretende verificar o crescimento econômico da comunidade por meio do levantamento de todos os bens e serviços finais produzidos na região durante o período de um ano agrícola.

- Valor ganho mensalmente com a venda de produtos e afins: esse indicador deve levantar a média da renda por 1 hectare (ha) recebida pelos produtores rurais durante 12 meses do ano agrícola e, ao final, gerar a renda bruta anual desses produtores, ambas computadas em porcentagem do salário mínimo vigente. 
Tabela 2. Indicadores econômicos.

\begin{tabular}{|c|c|c|}
\hline \multicolumn{3}{|c|}{ Sustentabilidade econômica } \\
\hline Tema & Subtema & Indicador \\
\hline Estrutura Econômica & $\begin{array}{l}\text { Crescimento } \\
\text { econômico }\end{array}$ & PIB per capita da comunidade \\
\hline $\begin{array}{l}\text { Estrutura de renda } \\
\text { da propriedade }\end{array}$ & $\begin{array}{l}\text { Valor ganho } \\
\text { mensalmente com a } \\
\text { venda de produtos e } \\
\text { afins }\end{array}$ & $\begin{array}{l}\text { Renda em porcentagem do salário mínimo } \\
\text { vigente por hectares (ha) }\end{array}$ \\
\hline \multirow{2}{*}{$\begin{array}{l}\text { Consumo e padrões } \\
\text { de } \\
\text { produção }\end{array}$} & \multirow[b]{2}{*}{ Uso de Energia } & Consumo anual per capita de energia (Kw) \\
\hline & & $\begin{array}{l}\text { Investimentos em ações de energia renovavam e } \\
\text { não renováveis }\end{array}$ \\
\hline Emprego & $\begin{array}{l}\text { Geração de emprego } \\
\text { por unidade familiar }\end{array}$ & $\begin{array}{l}\text { Numero de empregados dentro da unidade } \\
\text { familiar, formal ou informalmente }\end{array}$ \\
\hline Mão de obra & $\begin{array}{c}\text { Tipos de mão de obra } \\
\text { utilizada na } \\
\text { propriedade }\end{array}$ & $\begin{array}{l}\text { Quantidade de mão de obra familiar, permanente } \\
\text { e eventual utilizada por unidade produtiva }\end{array}$ \\
\hline $\begin{array}{l}\text { Diversidade de } \\
\text { produção }\end{array}$ & $\begin{array}{c}\text { Aproveitamento } \\
\text { econômico da } \\
\text { propriedade pelos } \\
\text { diversos tipos de usos }\end{array}$ & $\begin{array}{l}\text { Agricultura, pecuária, reflorestamento comercial, } \\
\text { turismo, serviços ambientais ou outros }\end{array}$ \\
\hline $\begin{array}{l}\text { Rentabilidade } \\
\text { econômica da } \\
\text { produção } \\
\end{array}$ & $\begin{array}{l}\text { Rentabilidade dos } \\
\text { produtos produzidos }\end{array}$ & $\begin{array}{l}\text { Agricultura, pecuária, reflorestamento comercial, } \\
\text { turismo, serviços ambientais ou outros }\end{array}$ \\
\hline \multirow{2}{*}{$\begin{array}{l}\text { Estabilidade da } \\
\text { produção agrícola }\end{array}$} & \multirow{2}{*}{$\begin{array}{l}\text { Produção existente na } \\
\text { propriedade }\end{array}$} & Nos últimos dois anos \\
\hline & & Nos últimos dez anos \\
\hline Comercialização & Venda do produto final & Destino da produção \\
\hline
\end{tabular}

- Consumo e padrões de produção: avaliar três condições, ou seja, a disponibilidade de energia elétrica, e, em caso afirmativo, a quantidade em quilowatt (kW) ano de uso de energia no sistema produtivo e a existência e utilização de fontes de energia renováveis.

- Geração de emprego por unidade familiar: esse indicador avalia o número de indivíduos empregados dentro da unidade familiar, classificando-os em empregados formais ou informais.

- Utilização da mão de obra: Procura-se avaliar neste item quais formas de mão de obra são utilizadas na propriedade durante o ciclo produtivo, podendo ser: familiar, contratado mensalmente ou contratado diariamente (eventual), com ou sem carteira assinada.

- Diversidade de produção: busca-se avaliar, com esse indicador, quanto da propriedade está disponível para a produção e quanto dessa área está destinado ao uso para agricultura, pecuária, reflorestamentos comerciais, turismo, serviços ambientais e outros. Os valores serão informados em hectares (ha) e, posteriormente, transformados em porcentagem. Esses dados serão cruzados com a porcentagem de uso sustentável das áreas produtivas. 
- Rentabilidade da propriedade: avalia-se neste item a rentabilidade da propriedade em cada um dos segmentos acima mencionados, ou seja, na agricultura, pecuária, reflorestamentos comerciais, turismo, serviços ambientais e outros. Essa rentabilidade será informada em valores referentes à porcentagem do salário mínimo vigente.

- Estabilidade da produção agrícola: a produção agropecuária é cíclica, ou seja, ela se desenvolve em função dos interesses do mercado local. Portanto, avaliam-se, neste item, quais das produções acima citadas foram desenvolvidas nos últimos dois anos e nos últimos dez anos na propriedade, com o intuito de reconhecer formas de produção que possam gerar, futuramente, estabilidade econômica local.

- Comercialização: a venda do produto final é de suma importância em qualquer cadeia produtiva, portanto nesse contexto avalia-se o destino de sua produção, podendo ser para subsistência, para o mercado local informal, para o mercado local formal, para cooperativas, ou outras formas de comercialização que serão informadas.

É imprescindível que a interpretação da dinâmica demográfica e das condições de vida da população esteja atrelada aos fenômenos relativos à produção, à distribuição e ao consumo de bens e serviços. Dessa forma, devem ser identificadas as atividades econômicas e seu arranjo no território. Da mesma maneira, deve ser enfatizada a polarização, bem como os fluxos de produção e dos trabalhadores. Devem-se observar as alterações que ocorreram no passado e as tendências de ocorrência de mudança ao longo do tempo, pois essa compreensão conduz à elaboração de alternativas de ação em diferentes contextos, sempre tendo em vista a proteção do potencial econômico da terra ou do próprio sistema de produção.

\subsection{Indicadores da integridade ecológica}

Ressalta-se que, quanto mais um agroecossistema "imitar" um ecossistema, mais sustentável ele poderá ser. É necessário que não se busque apenas a sustentabilidade econômica, como acontece atualmente, mas também a estabilidade e a sustentabilidade ecológica, portanto, a otimização de todo o sistema (Altieri, 2000).

O desenvolvimento rural sustentável deverá resultar, não apenas na melhoria dos indicadores sociais e econômicos, mas também na preservação do meio ambiente. Assim, a questão ambiental deverá estar presente na formulação, implementação e avaliação das ações desenvolvidas.

Os indicadores ambientais da Tabela 3 podem ser descritos como:

- Mudanças climáticas: com esse indicador, pretende-se avaliar a emissão dos gases que contribuem para o efeito estufa no meio rural, principalmente o dióxido de carbono $\left(\mathrm{CO}_{2}\right)$ e o gás metano $\left(\mathrm{CH}_{4}\right)$.

- Uso da terra por tipo de culturas: por meio desse indicador busca-se levantar as áreas, em hectares, das terras utilizadas para culturas anuais, perenes, reflorestamento comercial com espécies exóticas e nativas, e as áreas de floresta nativa e áreas de preservação permanente existentes e em fase de recuperação. Essas áreas serão posteriormente transformadas em porcentagem da área total da microbacia. Pretendese levantar o número de propriedades que utilizam fertilizantes (quantidade) e agrotóxicos (quantidade e classe toxicológica), as áreas, em hectares, em processo de desertificação, sendo o solo exposto, por excesso de pisoteio animal nas pastagens, por deslizamento natural ou induzido, por desmatamento ou aterramento, e as áreas urbanizadas ou áreas de transição rural-urbana dentro da microbacia, podendo ser áreas legais ou ilegais, conforme legislação vigente. 
Tabela 3. Indicadores ambientais.

\begin{tabular}{|c|c|c|}
\hline \multicolumn{3}{|c|}{ Sustentabilidade ambiental } \\
\hline Tema & Subtema & Indicador \\
\hline Atmosfera & Mudança climática & $\begin{array}{l}\text { Emissão de gases que contribuem para o efeito estufa } \\
\text { (Dióxido de Carbono }-\mathrm{CO}_{2} \text { e Metano }-\mathrm{CH}_{4} \text { ) }\end{array}$ \\
\hline \multirow{7}{*}{ Terra } & \multirow{3}{*}{ Agricultura } & $\begin{array}{c}\text { Área de cultura agrícola anual, permanente e de } \\
\text { reflorestamento econômico com espécies exóticas e } \\
\text { nativas (ha) }\end{array}$ \\
\hline & & Uso de fertilizantes (t/ha) \\
\hline & & Uso de agrotóxicos (t/ha) \\
\hline & \multirow{2}{*}{ Florestas } & Área permanente de floresta (ha) \\
\hline & & Recuperação de mata nativa (ha) \\
\hline & Desertificação & Área desertificada (ha) \\
\hline & Urbanização & Área de urbanização legal e ilegal (ha) \\
\hline \multirow{3}{*}{$\begin{array}{l}\text { Recursos Hídricos - } \\
\text { Água }\end{array}$} & Quantidade de água. & $\begin{array}{c}\text { Percentagem de fornecimento anual de água } \\
\text { subterrânea e de superfície } \\
\text { por disponibilidade total de água }\end{array}$ \\
\hline & \multirow{2}{*}{ Qualidade da água } & $\begin{array}{c}\text { Demanda Bioquímica de oxigênio (DBO) em corpos } \\
\text { d'água }\end{array}$ \\
\hline & & $\begin{array}{l}\text { Concentração de coliformes fecais em corpos d'água } \\
\text { e água potável }\end{array}$ \\
\hline \multirow{3}{*}{ Biodiversidade } & \multirow{2}{*}{ Ecossistemas } & Áreas protegidas (ha) \\
\hline & & Porcentagem da área protegida por área total \\
\hline & Espécies & Abundância das espécies protegidas (nº. de sp/ha) \\
\hline $\begin{array}{l}\text { Fragilidade do } \\
\text { ambiente físico }\end{array}$ & $\begin{array}{l}\text { Potencial de fragilidade } \\
\text { do ambiente natural }\end{array}$ & $\begin{array}{c}\text { Conhecimento das características e da dinâmica } \\
\text { dos ambientes naturais com ou sem intervenções } \\
\text { humanas }\end{array}$ \\
\hline \multirow{2}{*}{ Resíduos sólidos } & \multirow{2}{*}{$\begin{array}{l}\text { Deposição dos resíduos } \\
\text { sólidos }\end{array}$} & Área urbana \\
\hline & & Área rural \\
\hline \multirow{2}{*}{ Ambiente } & Cobertura Vegetal & $\begin{array}{l}\text { Percentual de cobertura vegetal existente } \\
\text { disponibilizada ao público em geral }\end{array}$ \\
\hline & Segurança ambiental & $\begin{array}{l}\text { Número de ocorrências oficiais de transtornos } \\
\text { ambientais }\end{array}$ \\
\hline Educação & Educação Ambiental & $\begin{array}{l}\text { Existência de projeto na comunidade; e, } \\
\text { Porcentagem da população conscientizada sobre a } \\
\text { melhoria do sistema de produção agrícola adaptado } \\
\text { ao ambiente com garantias de geração de renda e } \\
\text { adoção de tecnologias menos agressivas ao ambiente }\end{array}$ \\
\hline
\end{tabular}

- Água: esse indicador busca levantar a quantidade de água disponível por habitante (superficial ou subterrânea) e sua relação com a água total disponível em porcentagem; a demanda Bioquímica de oxigênio em corpos d'água da microbacia e a concentração de coliformes fecais em corpos d'água da microbacia e em água potável recebida pela população. 
- Biodiversidade: esse indicador busca demonstrar a saúde do ecossistema, ou seja, as áreas protegidas, a porcentagem dessas áreas em relação à área total da microbacia e à abundância de espécies protegidas.

- Fragilidade do ambiente físico: esse indicador deve demonstrar a conscientização da população sobre a fragilidade do ambiente em que vive, e deverá ser medido pela porcentagem da população com esse tipo de conhecimento e sobre os cuidados que são tomados em relação a esse ambiente.

- Disposição dos resíduos sólidos: esse indicador busca demonstrar como a população realiza o tratamento dos resíduos sólidos primeiramente em relação ao lixo: onde é depositado, se existe separação de lixo reciclável e qual seu destino, e se ocorre aproveitamento do lixo orgânico. Em relação ao tratamento de esgoto, se é atendido por rede coletora e, se não for, se existe algum tipo de tratamento residencial (em caso afirmativo, deve-se informar o tipo de tratamento).

- Ambiente: esse indicador deverá levantar o porcentual de cobertura vegetal existente disponibilizada ao público em geral e o número de ocorrências oficiais de transtornos ambientais, principalmente queimadas, corte de espécies nativas, poluição de córregos, entre outros.

- Educação Ambiental: deve-se levantar a existência de projeto de educação ambiental desenvolvido na comunidade e os órgãos envolvidos nisso, bem como o conhecimento das ações desse projeto e a participação da comunidade.

Assad e Almeida (2004) afirmam que atividade agrícola requer certos desafios para governos, sociedade e agricultores, podendo ocorrer em cinco vertentes, representadas por: desafio ambiental (busca de sistema de produção agrícola adaptado ao ambiente, minimizando a dependência de insumos externos e de recursos naturais não renováveis); desafio econômico (adoção do sistema de produção e de cultivo que diminua as perdas e desperdícios, apresentando produtividade compatível com os investimentos feitos, e estabelecendo mecanismos que assegurem o êxito do produto agrícola nos mercados interno e externo); desafio social (procura de sistema de produção que garanta a geração de renda para o trabalhador rural e condições de trabalho com remuneração compatível com sua importância no processo); desafio territorial (viabilização de uma efetiva integração agrícola com o espaço rural); e, desafio tecnológico (a necessidade de desenvolver tecnologias menos agressivas ao ambiente, mantendo adequação na relação produção/produtividade).

\subsection{Indicadores institucionais}

A dinâmica humana só é bem entendida se os temas relativos à demografia, condições de vida, economia, entre outros, forem interpretados de acordo com os significados das políticas passadas e atuais estabelecidas para o local em questão.

A interpretação dos instrumentos de gestão política que vigoram na região informa sobre as respostas que a sociedade dá para os problemas socioeconômicos e ambientais e sobre sua expectativa sobre o desenvolvimento local. Essa visão global dos instrumentos de gestão é vital para o estabelecimento de um elo entre o trabalho técnico e o político. Além disso, a sobreposição de planos, programas e outros instrumentos podem esclarecer alguns conflitos ocorrentes no local.

Os indicadores institucionais da Tabela 4 podem ser descritos como:

- Intervenção pública no ambiente: identificação dos impactos ocasionados por obras públicas e seu impacto no meio ambiente, na economia local e no bem-estar da comunidade. 
- Preservação de áreas críticas e/ou reconstituídas: reconhecimento dessas áreas pelo poder público, estado em que se encontram e cuidados que recebem.

- Desenvolvimento de projetos sustentáveis na área: identificação de projetos de desenvolvimentos sustentáveis na comunidade; entidades públicas envolvidas; entidades da sociedade civil envolvidas; conhecimento da existência do projeto, pela comunidade e sua participação. No caso de não existirem, identificar o anseio da comunidade pela implantação e desenvolvimento de projetos.

- Legislação incidente: identificação dos principais regulamentos legais aplicáveis à área de planejamento e listagem de benefícios e prejuízos trazidos por eles, de acordo com a avaliação da população local.

- Estrutura e organização: estrutura administrativa existente no poder público para ações em desenvolvimento sustentável da comunidade (número de órgãos e funcionários); existência de organismos descentralizados de gestão (quantidade) e sua atuação na comunidade; existência de organização social e ambiental atuante na comunidade (número de entidades e finalidade); programas e instrumentos de planejamento e gestão desenvolvidos na comunidade.

Tabela 4. Indicadores institucionais.

\begin{tabular}{|c|c|c|}
\hline \multicolumn{3}{|c|}{ Sustentabilidade institucional } \\
\hline Tema & Subtema & Indicador \\
\hline $\begin{array}{c}\text { Intervenção pública } \\
\text { no ambiente }\end{array}$ & $\begin{array}{l}\text { Impacto de obras de } \\
\text { intervenção }\end{array}$ & $\begin{array}{l}\text { Aferição desse impacto por área e gravidade do } \\
\text { dano ambiental, social e econômico }\end{array}$ \\
\hline $\begin{array}{l}\text { Preservação de áreas } \\
\text { críticas e/ou } \\
\text { reconstituídas }\end{array}$ & $\begin{array}{l}\text { Estudo da preservação } \\
\text { dessas áreas }\end{array}$ & $\begin{array}{l}\text { Aferição da área e do estado de regeneração que } \\
\text { elas se encontram }\end{array}$ \\
\hline \multirow{2}{*}{$\begin{array}{l}\text { Desenvolvimento de } \\
\text { projetos sustentáveis } \\
\text { na área }\end{array}$} & Políticas públicas & \multirow[b]{2}{*}{$\begin{array}{l}\text { Participação da comunidade e resultados do } \\
\text { projeto }\end{array}$} \\
\hline & $\begin{array}{c}\text { Sociedade civil } \\
\text { organizada }\end{array}$ & \\
\hline Leis & Legislação incidente & $\begin{array}{l}\text { Regulamentos legais ambientais e de interesse } \\
\text { local }\left(n^{\circ} .\right)\end{array}$ \\
\hline \multirow{5}{*}{$\begin{array}{l}\text { Estruturas e } \\
\text { organizacão }\end{array}$} & Pode público municipal & Estrutura administrativa $\left(\mathrm{n}^{\mathrm{o}}.\right)$ \\
\hline & $\begin{array}{l}\text { Organismos } \\
\text { descentralizados de } \\
\text { gestão }\end{array}$ & Participação de organismos descentralizados \\
\hline & $\begin{array}{l}\text { Organizações não } \\
\text { governamentais }\end{array}$ & Participação de organizações sociais e ambientais \\
\hline & Programa e projetos & Programas de planejamento e gerenciamento \\
\hline & Instrumentos de gestão & Instrumento de planejamento e gerenciamento \\
\hline
\end{tabular}

No conjunto de temas que demandam pactuação entre os atores públicos e privados, a questão ambiental ganha relevância. O desafio é integrar a ação das entidades ambientalistas e dos movimentos sociais representados pelos diversos segmentos das populações rurais num projeto que reconheça e valorize a participação dessas comunidades na estratégia de conservação da biodiversidade e do uso sustentável dos recursos naturais.

O rural é um espaço a ser conquistado pela democracia participativa. A ampliação da presença do Estado na área rural não pode significar a imposição de uma visão centralizada sobre o meio rural. As experiências de relação entre Estado e sociedade precisam ser mais bem articuladas, no sentido de atendimento às necessidades e anseios locais.

Modificações em vários aspectos de ordem legal e de caráter normativo são necessários, especialmente aqueles ligados à legislação sanitária aplicada à agroindústria familiar; legislação ambiental em áreas de preservação permanente; desburocratização das instituições 
que atuam no meio rural; e, criação de mecanismos facilitadores da atuação de entidades da sociedade civil como parceiros no processo de desenvolvimento rural sustentável, incluindose a gestão de fundos públicos.

\subsection{Indicadores da saúde social ou qualidade de vida}

Condição de vida é uma expressão designada a explicitar as desigualdades sociais, fornecer indícios da dinâmica social e definir as ligações entre esses fatos e a qualidade do ambiente natural.

A inclusão concebida como democratização da sociedade brasileira abrange a ampliação da participação política e social e do protagonismo econômico da agricultura e produção familiar.

Os indicadores sociais selecionados estão apresentados na Tabela 5 e descritos abaixo.

- Equidade: identificação da porcentagem de pessoas vivendo abaixo da linha de pobreza; a iniquidade social e o número de pessoas, na idade de labor, sem emprego formal ou informal; é a razão entre o número de empregos formais entre homens e mulheres e a razão do salário médio entre eles.

- Padrões socioeconômicos do indivíduo: identificar a faixa etária dos moradores da comunidade, classificando-os conforme faixa etária, ou seja, quantidade de indivíduos de 0 a 6 anos; 6 a 15 anos; 15 a 45 anos; 45 a 65 anos; acima de 65 anos. Neste item, diferencia-se o número de homens e mulheres em cada faixa etária. Além disso, como se busca conhecer a entidade familiar, procede-se a um levantamento do número de integrantes das famílias, observando-se o número de homens e mulheres e a idade de cada um.

- Educação: identifica o nível de educação básica na comunidade. Esse indicador informa sobre: porcentagem de crianças fora da escola antes dos 15 anos de idade, ou seja, antes de completar o ensino fundamental - ciclos I e II -, primeira fase da educação básica, ou percentagem de crianças fora da escola fundamental após 9 anos de permanência; porcentagem de analfabetos e analfabetos funcionais entre os adultos; $\mathrm{o}$ atendimento à demanda educacional, ou seja, o número de matrículas em nível infantil, fundamental, médio, médio profissionalizante e superior em relação ao número de indivíduos da comunidade com idades específicas para cada nível de estudo; porcentagem de evasão e reprovação dos alunos por ciclo escolar e as razões indutoras e seus respectivos percentuais.; distância das residências até as escolas frequentadas pelos indivíduos da comunidade; e, existência de transporte público e valor cobrado. Deve-se reconhecer o nível de formação profissional em relação à atividade produtiva e ao conhecimento informal dos indivíduos que trabalham na comunidade, e também em relação ao número de cursos realizados, número de palestras assistidas ou informações obtidas por meio de veículos de comunicação. Nesse caso, o indivíduo pode informar outros meios de aquisição de conhecimento informal. 
Tabela 5. Indicadores sociais.

\begin{tabular}{|c|c|c|}
\hline \multicolumn{3}{|c|}{ Sustentabilidade social } \\
\hline Tema & Subtema & Indicador \\
\hline \multirow{5}{*}{ Equidade } & \multirow{3}{*}{ De pobreza } & $\begin{array}{l}\text { Percentagem da população vivendo abaixo da linha de } \\
\text { pobreza }\end{array}$ \\
\hline & & Iniquidade social \\
\hline & & Taxa de desemprego \\
\hline & \multirow{2}{*}{ De gênero } & $\begin{array}{l}\text { Razão do salário feminino médio pelo salário masculino } \\
\text { médio }\end{array}$ \\
\hline & & Razão de empregados formais (masculino/feminino) \\
\hline \multirow{2}{*}{$\begin{array}{l}\text { Padrões } \\
\text { socioeconômicos }\end{array}$} & \multirow{2}{*}{ De indivíduos } & Faixa etária \\
\hline & & Estrutura familiar (número de integrantes). \\
\hline \multirow{10}{*}{ Saúde } & Status Nutricional & Status Nutricional das crianças \\
\hline & \multirow{3}{*}{ Mortalidade } & Coeficiente de mortalidade geral \\
\hline & & Coeficiente de mortalidade até cinco anos de idade \\
\hline & & Expectativa de vida ao nascer \\
\hline & Saneamento & $\begin{array}{c}\text { Percentagem da população com dispositivos de } \\
\text { esgotamento sanitário }\end{array}$ \\
\hline & Água potável & Percentagem da população com acesso à água tratada. \\
\hline & \multirow{4}{*}{$\begin{array}{l}\text { Distribuição da } \\
\text { Atenção à Saúde }\end{array}$} & $\begin{array}{l}\text { Percentagem da população com acesso às unidades de } \\
\text { atenção primária à saúde }\end{array}$ \\
\hline & & Imunização contra doenças infecciosas infantis \\
\hline & & Doenças e situações epidemiológicas \\
\hline & & Coeficiente de prevalência contraceptiva \\
\hline \multirow{9}{*}{ Educação } & Nível de educação & $\begin{array}{c}\text { Percentagem das crianças fora da escola antes dos } 15 \text { anos } \\
\text { de idade. }\end{array}$ \\
\hline & Alfabetização & Taxa de analfabetismo de adultos $\left(\mathrm{n}^{\mathbf{o}}\right.$.) \\
\hline & $\begin{array}{c}\text { Atendimento a } \\
\text { demanda educacional }\end{array}$ & $\begin{array}{c}\text { Matriculas em nível infantil, fundamental, médio, médio } \\
\text { profissionalizante e superior }\left(\mathrm{n}^{\mathbf{o}} .\right)\end{array}$ \\
\hline & Desempenho escolar & $\begin{array}{l}\text { Taxas de evasão e reprovação por ciclo escolar e percentual } \\
\text { das razões indutoras }\end{array}$ \\
\hline & Acesso e localização & Estimativas de distância para acesso à escola \\
\hline & $\begin{array}{l}\text { Formação } \\
\text { Profissional }\end{array}$ & $\begin{array}{l}\text { Nível de formação profissional em relação à atividade } \\
\text { produtiva }\end{array}$ \\
\hline & \multirow{3}{*}{$\begin{array}{l}\text { Conhecimento } \\
\text { informal }\end{array}$} & Número de cursos realizados \\
\hline & & Número de palestras assistidas \\
\hline & & Informações obtidas por meio de veículos de comunicação \\
\hline Moradia & Condições de & Área construída de moradia por pessoa $\left(\mathrm{m}^{2}\right)$ \\
\hline \multirow{6}{*}{ Infraestrutura } & \multirow{6}{*}{ De serviços } & Acessos e circulações em locais públicos $\left(\mathrm{n}^{\circ}\right.$.) \\
\hline & & Eletricidade (acesso a energia elétrica) \\
\hline & & Meios de transporte \\
\hline & & Meios de comunicação \\
\hline & & Equipamentos de recreação \\
\hline & & Banheiros por residência $\left(n^{\circ}.\right)$ \\
\hline \multirow{3}{*}{ Segurança } & \multirow{3}{*}{ Crime } & Numero de crimes ocorridos por grupo de 1000 pessoas \\
\hline & & Atendimento policial \\
\hline & & Segurança patrimonial, habitacional, de trânsito e pessoal \\
\hline \multirow{2}{*}{ População } & \multirow{2}{*}{$\begin{array}{c}\text { Mudanças } \\
\text { demográficas }\end{array}$} & Taxa de crescimento da população \\
\hline & & Moradias formalmente regularizadas ou não $\left(\mathrm{n}^{\circ}\right.$.) \\
\hline \multirow{5}{*}{ Comunidade } & \multirow{5}{*}{$\begin{array}{l}\text { Conviver em } \\
\text { comunidade }\end{array}$} & Participação em cultos religiosos $\left(\mathrm{n}^{\circ}.\right)$ \\
\hline & & Participação na organização das festas da comunidade $\left(n^{\circ}\right.$.) \\
\hline & & Participação nas festas da comunidade $\left(\mathrm{n}^{\circ}.\right)$ \\
\hline & & $\begin{array}{c}\text { Participação efetiva em associação ou outra forma ou } \\
\text { informal organizacional }\left(\mathrm{n}^{\circ} .\right)\end{array}$ \\
\hline & & $\begin{array}{l}\text { Participação como ouvinte em reuniões de associação ou } \\
\text { outra forma organizacional formal ou informal }\left(n^{o}{ }^{\circ}\right)\end{array}$ \\
\hline
\end{tabular}


- Condições de moradia: área construída de moradia por indivíduo em cada residência.

- Infraestrutura de serviços: existência, em locais públicos, de acessos e circulações, porcentagem pelo total de comércio, entidades religiosas, entidades de lazer, escolas, locais de atendimento à saúde e demais locais públicos existentes; número de residências com acesso à energia elétrica; meios de transporte e de comunicação existente na comunidade; equipamentos públicos de recreação existentes na comunidade; número de banheiros por residência.

- Segurança: número de crimes registrados por grupos de 1.000 pessoas; número de atendimentos policiais efetuados mensalmente e número de eventos ocorridos em relação à segurança patrimonial, habitacional, de trânsito e pessoal.

- População: taxa anual de crescimento da população da comunidade; número de moradias rurais e urbanas existentes na comunidade formalmente regularizadas ou irregulares. Esse indicador é calculado com base na razão das moradias formalmente regularizadas por moradias irregulares.

- Convivência em comunidade: número de indivíduos do local participantes de cultos religiosos; em organização de festas da comunidade; nas festas da comunidade; com participação efetiva ou como ouvinte em reuniões da sociedade civil.

O foco desta pesquisa - o desenvolvimento local integrado e sustentável - é um campo em construção. $\mathrm{O}$ desenvolvimento de indicadores de sustentabilidade busca subsidiar as ações locais realizadas em prol do desenvolvimento sustentável. O desenvolvimento deve ser visto na sua forma mais ampla possível, a partir do atendimento mínimo das necessidades básicas da população, uma vez que "o desenvolvimento só poderá ser considerado efetivo [...] se este constituir-se em desenvolvimento humano, social e sustentável, pois, quando se fala em desenvolvimento, deve-se estar buscando a melhoria da vida das pessoas [...] e da sociedade como um todo" (Martinelli e Joyal, 2004).

O problema de geração de renda, tratado por meio do desenvolvimento econômico, requer, tanto uma política macroeconômica clara, quanto uma política local focalizada. As tendências naturais de longo prazo, como a queda do peso relativo da agricultura no crescimento econômico, bem como os processos de globalização, impõem sérios desafios. A área rural deve adaptar-se às estruturas econômicas em mudança e desenvolver a capacidade de competir em uma economia cada vez mais industrializada e modernizada e, ao mesmo tempo, buscar formas de produção que estejam adequadas ao meio ambiente local. Essa é uma nova situação para uma população que estava mais acostumada a uma economia muito fechada, e, em muitos casos, a uma economia de subsistência, ambas com caráter extensivo de produção.

O modelo atual de desenvolvimento agrícola tem como possíveis consequências a contaminação e degradação de solos e águas, desertificação, salinização, redução da biodiversidade e desequilíbrios ecológicos, levando, por fim, à insustentabilidade dos sistemas de produção agrícola. Assim, a agricultura tradicional vem perdendo espaço em relação às novas formas produtivas agrícolas, pois traz inúmeras desvantagens à saúde do solo, do ambiente e, principalmente, ao trabalhador rural e ao consumidor.

Portanto, o produtor ou agricultor deve ficar atento às novas formas de produção agrícola, pois a emergente agricultura sustentável concilia produção, qualidade, conservação e recuperação dos recursos naturais, o que só lhe trará vantagens, principalmente pela conscientização do consumidor, que se torna mais informado, conhecedor das formas de produção e qualidade dos produtos que adquire e que, assim, é mais exigente.

É um fato que a maior parte do crescimento econômico do município, na última década, não atingiu a população rural. O desenvolvimento econômico da área rural, além do 
suprimento das necessidades locais, requer, de início, a solução de obstáculos que geralmente inibem a capacidade de alcançar níveis de produtividade aceitáveis, como infraestruturas, capital humano, tecnologias, estruturas institucionais, acesso ao financiamento e mercados, e conhecimento técnico.

A sustentabilidade da comunidade local está vinculada ao grau de articulação e de eficiência na produção interna de seus sistemas produtivos e na construção social dos mercados locais, e isso pressupõe a construção de uma infraestrutura básica que esteja vinculada a uma propriedade produtiva. Para dinamizar uma determinada potencialidade, o primeiro ponto é a identificação de uma ou mais vocações, descobrindo, assim, as vantagens da localidade e comparando-as com as demais.

Toda localidade é única, singular, com identidade própria, com suas vocações, seus problemas e limites. A partir da identificação das potencialidades, devem ser elaborados planos que possam desenvolvê-las e dinamizá-las. Entende-se por potencialidades os recursos disponíveis ou com possibilidade de serem disponibilizados em uma determinada localidade.

A formação profissional é um elemento estratégico para implementação de qualquer política de desenvolvimento econômico a fim de garantir as mudanças propostas pelo Desenvolvimento Sustentável. As ações devem ser realizadas como instrumento que possibilite aos trabalhadores o resgate da autoestima e o desenvolvimento de suas habilidades e aptidões produtivas, transformando-os em atores capacitados em assumir a gestão desse novo modelo de desenvolvimento.

Atualmente, existe um vertiginoso crescimento da demanda pelos produtos da agropecuária, pois há preocupação com processos produtivos que não degradem os recursos naturais de maneira irreversível, o que torna necessário o investimento educacional em capital humano na busca de novas estratégias para um desenvolvimento rural sustentável.

Azevedo (2000), após uma revisão bibliográfica para investigar os fatores que prevalecem nas decisões dos produtores rurais de várias partes do mundo, quanto à preservação ambiental, concluiu que há concordância, entre todos os autores estudados, quanto à preponderância do fator econômico. Isto é, as decisões, pelo produtor rural, relacionadas à preservação de determinados ecossistemas, estão baseadas no pressuposto de que preservar implica perda econômica, decorrente da desvalorização do capital - terra -, da perda de rendimentos que seriam gerados com a exploração da área e com a sua manutenção, já que os danos ambientais, advindos da não preservação, não são contabilizados.

Por outro lado, Galjart (1979) sustenta que as questões relacionadas, de maneira geral, ao desenvolvimento agrícola podem ser classificadas em três itens:

- Ignorância (o agricultor não sabe fazer outras coisas além daqueles que tem feito);

- Incapacidade (o agricultor sabe o que deveria fazer, mas é incapaz de fazê-lo, por motivos financeiros ou por outras razões);

- Desinteresse (o agricultor sabe o que deveria fazer e pode fazê-lo, mas prefere seguir outros valores).

Essa classificação pode ser relacionada, no contexto da presente discussão, aos aspectos que influenciam o produtor rural quanto à preservação do meio ambiente. A ignorância seria referente ao desconhecimento das vantagens de da preservação da natureza e da importância das leis ambientais.

A incapacidade - o produtor tem conhecimento da necessidade de preservação da natureza e do respeito às leis ambientais, mas não é capaz, financeiramente ou por diversas outras razões, de implementar práticas de preservação ou restauração ambientais.

O desinteresse representaria sua preferência em não fazê-lo, podendo ser influenciado por questões culturais. 
A ignorância e o desinteresse podem ser combatidos com a difusão do conhecimento e o envolvimento dos aspectos culturais em trabalhos de extensão rural. A incapacidade pode ser minimizada com políticas públicas adequadas, crédito agrícola e incentivos, como os oferecidos pelos programas estaduais de microbacias em parceria com o Banco Mundial, e com estruturação e comercialização da produção familiar, entre outros.

A sustentabilidade em pequenas comunidades rurais, como a microbacia em estudo, é um dos maiores desafios dos governos municipais, atualmente. No caso específico do local de estudo, onde as problemáticas são muitas, exige-se, antes da realização de um trabalho de desenvolvimento sustentável, a elaboração de um inventário das instituições que possuam propostas metodológicas similares e com atuações diversificadas que possibilitem trabalhar a sustentabilidade econômica, ambiental e social em todos os seus parâmetros.

\section{CONSIDERAÇÕES FINAIS}

A questão dos indicadores - e de sua escolha - é essencial, sobretudo porque se trata de um conceito tão recente e complexo como o da sustentabilidade. Pensar no problema da escolha dos indicadores conduz a especificar, com o maior rigor, o que se fala quando se evoca a sustentabilidade da agricultura. O enfoque deverá ir além dos efeitos de moda, das perdas ou recuperações, e esse exercício, indispensável, permitirá clarear e ilustrar os seus objetivos. A elaboração de uma grade de indicadores, como realizado neste estudo, antes de tudo, é um exercício de explicitação do conceito de sustentabilidade em sua aplicação na agricultura, o que explica toda sua importância pedagógica. No entanto, a grade de indicadores é, neste caso, uma ferramenta de diagnóstico, de ajuda na elaboração do projeto e no decorrer de sua aplicação. Assim, interessa tanto ao desenvolvimento quanto à formação.

Nesta pesquisa pôde-se observar que a sustentabilidade da agricultura vem sendo defendida por diversos órgãos públicos e por diferentes segmentos sociais. Mesmo assim, ela ainda se apresenta de forma utópica, pois as alternativas de manejo sustentável se confrontam com os interesses econômicos distintos, ainda que se observem melhoras na relação agricultura e ambiente, por meio de técnicas consideradas menos agressivas. Observa-se também que nem sempre essa melhora é associada a uma sustentabilidade social, já que ela se impõe muito mais pelo aporte da questão ambiental do que pelo aporte da sustentabilidade social.

A seleção de indicadores de sustentabilidade permite a adoção do enfoque sistêmico, por meio da escolha de parâmetros sociais, econômicos e ambientais que possam ser demonstrados num período de tempo específico, determinando índices mensuráveis que expressem a realidade de uma região. Espera-se que os indicadores selecionados neste trabalho sejam testados pelos gestores públicos para a promoção do entendimento da dinâmica social, econômica e ambiental da agricultura familiar. Também poderão servir de apoio para a formulação e execução de políticas direcionadas à sustentabilidade da microbacia.

A ênfase na complexidade, trazida pela ideia de sustentabilidade, desafia os pesquisadores e técnicos a realizarem um trabalho interdisciplinar. Isso determina a quebra de barreiras entre os diferentes "setores" da ciência, num espírito de cooperação que termina por dinamizar as atividades.

Finalmente, a preocupação com os indicativos da sustentabilidade dos sistemas leva a um olhar mais atento da realidade rural e agrícola, e também a um entendimento mais amplo do desenvolvimento rural. O desafio colocado é o de evidenciar e internalizar a diversidade da realidade e de pensamento, em todas as suas dimensões, e procurar, nessa diversidade, soluções e propostas que de forma efetiva contribuam para a valorização da Vida. 


\section{REFERÊNCIAS}

ALTIERI, M. Agroecologia: a dinâmica produtiva da agricultura sustentável. 2. ed. Porto Alegre: Ed. Universidade, 2000.

ARGUELLO, F. V. P.; SAUSEN, T. M. Geografia: localização e aspectos físicos. In: FERREIRA, P.C. P. A. A biologia e a geografia do Vale do Paraíba: trecho paulista. São José dos Campos: IEPA, 2007. p. 9-34.

ASSAD, M. L. L.; ALMEIDA, J. Agricultura e sustentabilidade: contexto, desafios e cenários. Ciência \& Ambiente, n. 29, p. 15-30, 2004.

AZEVEDO, R. A. B. de. Estrutura conceitual para avaliação e monitoramento dos projetos do PDA com base em indicadores. Brasília: PPG7/PDA, 2000. (Relatório Técnico).

BRASIL. Secretaria da Educação Fundamental. Parâmetros curriculares. Brasília, 1998.

BUARQUE, S. C.; BEZERRA, L. Projeto de desenvolvimento municipal sustentável - bases referenciais. In: INSTITUTO INTERAMERICANO DE COOPERAÇÃO PARA A AGRICULTURA- IICA. Projeto Áridas. [S.1.]: IICA, 1994.

CASTELLS, M.; BORJA, J. As cidades como atores políticos. Novos estudos, n. 45, julho 1996. Disponível em: http://www.acsmce.com.br/wp-content/uploads/2012/10/AS-CIDADESCOMO-ATORES-POL\%C3\%8DTICOS.pdf. Acesso em: 11 dez. 2013.

D'AMBRÓSIO, U. Conhecimento e consciência o despertar de uma nova era. In: HOYOS GUEVARA, A. J. et al. Conhecimento, cidadania e meio ambiente. São Paulo: Peirópolis, 1998. cap. 1, p. 11-46.

DUMANSKI, J.; PIERE, C. Land quality indicators: research plan. Agriculture, Ecosystems \& Environment, v. 81, p. 93 - 102, 2000. http://dx.doi.org/10.1016/S0167-8809(00)00183-3

EHLERS, E. Agricultura sustentável: origens e perspectivas de um novo paradigma. 2. ed. Guaíba: Agropecuária, 1999.

GALJART, B. Rural development and sociological concepts: a critique. Rural Sociology, Bozenan, v. 36, n. 11, p. 31-41, 1979.

GONÇALVES, C. W. P. Os (des)caminhos do meio ambiente. 8. ed. São Paulo: Contexto, 2001.

HAVERI, A. Strategy of comparative advantage in local communities. Disponível em: http://www.cati.sp.gov.br/novacati/pemh/doc_pub/Metodologia. Acesso em: jul. 2007.

HOYOS GUEVARA, A. J. H. As relações entre o natural e o artificial e suas implicações educacionais. In: HOYOS GUEVARA, A. J. et. al. Conhecimento, cidadania e meio ambiente. São Paulo: Peirópolis, 1998.

INSTITUTO BRASILEIRO DE GEOGRAFIA E ESTATÍSTICA - IBGE. Resultados do censo demográfico 2000. Rio de Janeiro, 2006.

LANDAIS, E. Agriculture durable: les fondements d'un nouveau contrat social ? Courier de l'environnement de l'INRA, Paris, n. 33, p. 5-22, 1998.

MARTINELLI, D. P.; JOYAL, A. Desenvolvimento local e o papel das pequenas e médias empresas. Barueri: Manole, 2004. 
QUIRINO, T. R. Impacto agroambiental: perspectiva, problemas e prioridades. Rio de Janeiro: Embrapa, 1990. 183p.

SACHS, I. Desarrollo sustentable, bio-industrialización descentralizada y nuevas configuraciones rural-urbanas. El caso de la India y el Brasil. Pensamiento Iberoamericano, n. 16, p. 235-256, 1989.

SANTOS, R. F. Planejamento ambiental: teoria e prática. São Paulo: Oficina de Textos, 2004. 184p.

SÃO PAUlO (Estado). Secretaria do Meio Ambiente. Unidade de Conservação. São Paulo, 1998. Disponível em: http://www.sma.sp.gov.br. Acesso em: 16 ago. 2008.

SKOPURA, L. A. Áreas de preservação permanente e desenvolvimento sustentável, Jaguariúna: EMBRAPA Meio Ambiente, 2003. 